\title{
ABSCESSO ESPLÊNICO: MUDANÇAS NOS FATORES DE RISCO E NAS OPÇÕES DETRATAMENTO
}

\section{SPLENIC ABSCESS: CHANGES IN RISK FACTORS AND THERAPEUTHICAL OPTIONS}

\author{
Antonio Cavalcanti de Albuquerque Martins, TCBC-PE'; Luiz Felipe Duarte Fernandes Vieira²; \\ Álvaro Antonio Bandeira Ferraz, TCBC-PE³; Miguel Arcanjo dos Santos Júnior,TCBC-PE; \\ Edmundo Machado Ferraz, TCBC-PE ${ }^{4}$
}

\begin{abstract}
RESUMO: Objetivos: A origem dos abscessos esplênicos está relacionada a episódios de bacteremia após infarto esplênico. Recentemente, a SIDA, a tuberculose, a imunossupressão e as neoplasias têm mudado a apresentação clínica desse abscesso. Tradicionalmente, o tratamento de escolha é a esplenectomia. Entretanto, a drenagem percutânea pode ser uma alternativa útil em casos selecionados $\mathrm{O}$ objetivo desse trabalho foi determinar o perfil dos pacientes com abscesso esplênico tratados em um hospital terciário. Método: Dados referentes aos pacientes atendidos no Serviço de Cirurgia Geral HC-UFPE no período de novembro de1993 a fevereiro de 2004 foram analisados. Sete pacientes dentre os 73094 tratados no período constituíram o objeto desse estudo. Resultados: Cinco pacientes foram tratados inicialmente com esplenectomia e dois por drenagem percutânea. Quatro pacientes (57\%) apresentavam abscessos secundários à imunossupressão, tuberculose ou doença neoplásica. Três (43\%) apresentavam abscessos decorrentes de infecção metastática (endocardite). A drenagem percutânea foi o único tratamento utilizado em um caso. Conclusão: Houve uma mudança no padrão clássico, e quase que exclusivo, de origem hematogênica do abscesso esplênico para abscessos decorrentes de uma condição de imunossupressão (câncer, tuberculose, transplantes etc.). Em casos selecionados, a drenagem percutânea pode ser a única forma de tratamento invasivo utilizada (Rev. Col. Bras. Cir. 2005; 32(5): 337-341).
\end{abstract}

Descritores: Abscesso; Baço; Esplenectomia; Drenagem; Infecção; Fatores de risco; Terapia.

\section{INTRODUÇÃO}

O abscesso esplênico é um processo supurativo que envolve o parênquima esplênico ou o espaço subcapsular. A frequência relatada nas séries de autópsias varia entre $0,14 \%$ a $0,67 \% \%^{1,2}$. Originariamente descrito por Hipócrates ${ }^{3}$, o abscesso esplênico permanece sendo motivo de relatos de casos e pequenas séries em algumas instituições, havendo menos de mil casos relatados na literatura mundial. Mesmo o baço estando constantemente exposto a agentes infecciosos, pelo próprio papel que desempenha, abscessos do seu parênquima são raros ${ }^{1,4,5}$.

Caldarera $^{6}$ inferiu que a maior parte dos pacientes acometidos por um abscesso esplênico experimenta um infarto esplênico concomitante a um evento de bacteremia. Seu trabalho baseou-se na criação de um modelo experimental de abscesso esplênico, onde coelhos, cujos baços eram previamente traumatizados ou submetidos à ligadura arterial, recebiam uma solução contendo Staphilococcus aureus.

Na era pré-antibiótico, o abscesso esplênico era uma doença letal, devido ao diagnóstico tardio, muitas vezes postmortem. Atualmente, a tomografia computadorizada do abdome é a principal arma utilizada nesse diagnóstico. Sua sensibilidade é de $96 \%$, superior à ultra-sonografia (76\%) e à cintilografia hepatoesplênica $(75 \%)^{7}$.
Os organismos mais frequentemente implicados são Staphylococcus aureus, Streptococcus viridans, bacilos Gram negativos, como Klebsiella species e Salmonella enteritidis e fungos, representado por Candida species.

A terapêutica inclui a antibioticoterapia por um período não inferior a 14 dias. Inicialmente, o tratamento é de largo espectro. Se houver isolamento do microorganismo, antibioticoterapia específica deve ser realizada 5,8,9. O tratamento clássico preconizado é a esplenectomia ${ }^{7,9,10}$. Recentemente, com o aperfeiçoamento dos métodos de imagem, foi possível a introdução de drenagem percutânea guiada ${ }^{8}$.

A SIDA, o abuso de drogas intravenosas, quimioterapia, tuberculose e os transplantes têm mudado o perfil dos pacientes portadores desta doença em hospitais terciários ${ }^{7,10}$.

O objetivo desse trabalho foi determinar o perfil dos pacientes com abscesso esplênico tratados em um hospital terciário (Hospital das Clínicas da Universidade Federal de Pernambuco) nos últimos 10 anos e analisar as mudanças na apresentação clínica e nas opções terapêuticas utilizadas.

\section{MÉTODO}

Registros de pacientes atendidos pelo Serviço de Cirurgia Geral do Hospital das Clínicas da Universidade Fede-

1. Professor Substituto, HC-UFPE.

2. Médico Residente em Cirurgia Geral, HC-UFPE.

3. Professor Adjunto, HC-UFPE.

4. Professor Titular e Chefe do Serviço de Cirurgia Geral, HC-UFPE.

Recebido em 14/10/2005

Aceito para publicação em 01/12/2005

Conflito de interesse: nenhum

Fonte de financiamento: nenhuma

Trabalho realizado no Serviço de Cirurgia Geral do Hospital das Clínicas da Universidade Federal de Pernambuco. 


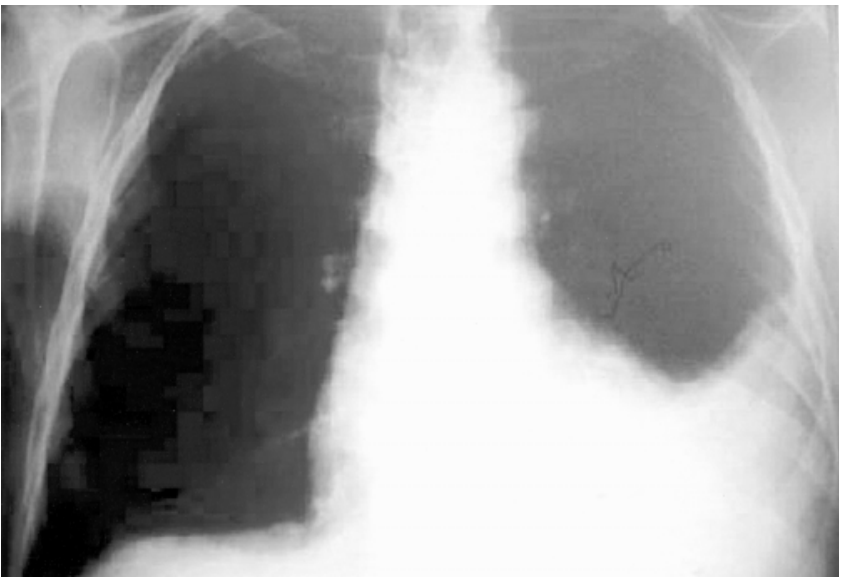

Figura 1 - Caso 6. Radiografia de tórax. Elevação da hemicúpula diafragmática e derrame pleural esquerdo.

ral de Pernambuco no período de novembro de 1993 até fevereiro de 2004 foram analisados. Dados demográficos, sinais e sintomas, etiologia, mortalidade, morbidade, esquema e duração da antibioticoterapia, tempo de hospitalização e achados histopatológicos foram estudados.

Os pacientes foram incluídos quando um ou mais desses critérios estiveram presentes: 1. Exame histopatológico do baço na autópsia ou peça cirúrgica mostrando esplenite ou formação de abscesso. 2. Sinais e sintomas de infecção intrabdominal combinados à tomografia com evidências de lesão ou lesões hipodensas no baço consistentes com abscesso. 3. Achado cirúrgico de abscesso esplênico na laparotomia exploradora.

\section{RESULTADOS}

Sete pacientes com abscesso esplênico foram identificados dentre os 73094 pacientes atendidos, perfazendo um total de 0,01\%. A média de idade na apresentação foi de 44 anos, variando entre 14 e 77 anos. Seis pacientes eram do sexo feminino (86\%).
A febre foi o único sintoma presente em todos os pacientes. Outro sintoma bastante comum foi a dor abdominal, observada em cinco pacientes (71\%). Dor torácica só foi referida por um paciente que apresentava derrame pleural no hemitórax esquerdo (Figura 1). Outros sinais e sintomas incluíram esplenomegalia (57\%), perda de peso (43\%) e vômitos, diarréia, distensão abdominal e irritação peritoneal (um caso cada -14\%).

Infecções hematogênicas (3/7) e abscessos relacionados aos estados de imunossupressão (4/7) foram as principais causas encontradas. A disseminação hematogênica estava relacionada à endocardite bacteriana (100\%), enquanto as condições de imunodeficiência incluíram linfoma (Caso 1), lupus eritematoso em uso de esteróides (Caso 3), transplante renal (Caso 4) e tuberculose com hipotiroidismo (Caso 5) (Tabela 1).

Todos os pacientes foram submetidos à tomografia computadorizada e seis ao exame ultra-sonográfico do abdome. Três pacientes apresentavam abscesso único de aspecto uniloculado (43\%). Todos os casos apresentavam abscessos com mais de 10 cm, em mais de um diâmetro. Os demais casos (57\%) eram de abscessos múltiplos ou multiloculados como o abscesso secundário à tuberculose (Figura 2). A esplenomegalia esteve presente em todos os casos de abscesso único e em apenas um caso com abscessos múltiplos.

$\mathrm{O}$ esquema antibiótico mais utilizado incluiu ceftriaxona e metronidazol por 14 a 21 dias. Nas situações de abscessos originados a partir de endocardite, drogas antiestafilococos foram utilizadas (vancomicina e linezolida).

Nenhuma cultura de secreção do abscesso foi positiva. Apenas uma hemocultura e uma cultura de cateter venoso central foram positivas para $S$. aureus (Tabela 1).

Seis pacientes foram submetidos à esplenectomia (85\%). Apenas um caso foi tratado exclusivamente com drenagem percutânea (Figuras 3 e 4). O caso mais recente foi tratado inicialmente com drenagem percutânea, na tentativa de preservação esplênica. O procedimento foi realizado com sucesso, com drenagem inicial de $1000 \mathrm{ml}$ de secreção purulenta e melhora clínica e laboratorial. No entanto, 72h após a drena-

Tabela 1 - Pacientes Portadores de Abscesso Esplênico Tratados no Hospital das Clínicas entre Nov/1993 e Fev/2004.

\begin{tabular}{|c|c|c|c|c|c|c|c|c|c|}
\hline $\begin{array}{l}\text { Casol } \\
\text { Sexo }\end{array}$ & $\begin{array}{l}\text { Idade } \\
\text { (anos) }\end{array}$ & Sinais/Sintomas & Exame complementar & $\begin{array}{c}\text { Doenças } \\
\text { Associadas }\end{array}$ & Tratamento & Antibiótico & Resultado & Histopatológico & Culturas \\
\hline $\begin{array}{l}1 \\
F\end{array}$ & 57 & $\begin{array}{l}\text { Dor abdominal } \\
\text { Febre diária } \\
\text { Perda de peso }\end{array}$ & $\begin{array}{l}\text { TAC: abscesso esplênico } \\
14 \times 12 \times 8 \mathrm{~cm} \text { com } \\
\text { componente gasoso }\end{array}$ & $\begin{array}{l}\text { Trombose } \\
\text { venosa } \\
\text { profunda }\end{array}$ & Esplenectomia & $\begin{array}{l}\text { Ceftriaxone } \\
\text { Metronidazol } \\
\text { por } 14 \text { dias }\end{array}$ & $\begin{array}{l}\text { Alta hospitalar } \\
\text { no } 150 \text { DPO }\end{array}$ & $\begin{array}{l}\text { Linfoma esplênico de } \\
\text { grandes células com } \\
\text { componente abcedado }\end{array}$ & Negativas \\
\hline $\begin{array}{l}2 \\
F\end{array}$ & 28 & $\begin{array}{l}\text { Astenia } \\
\text { Febre diária } \\
\text { Perda de peso }\end{array}$ & $\begin{array}{l}\text { TAC: várias áreas } \\
\text { hipodensas sugestivas } \\
\text { de abscesso esplênico }\end{array}$ & $\begin{array}{l}\text { Endocardite } \\
\text { bacteriana }\end{array}$ & Esplenectomia & $\begin{array}{l}\text { Ampicilina } \\
\text { Gentamicina } \\
\text { por } 21 \text { dias }\end{array}$ & $\begin{array}{l}\text { Alta hospitalar } \\
\text { no 23o DPO }\end{array}$ & $\begin{array}{l}\text { Embolos sépticos } \\
\text { no baço }\end{array}$ & Negativas \\
\hline $\begin{array}{l}3 \\
F\end{array}$ & 22 & $\begin{array}{l}\text { Dor abdominal } \\
\text { Febre diária } \\
\text { Distensăo }\end{array}$ & $\begin{array}{l}\text { USG/TAC: áreas de } \\
\text { necrose liquefativa } \\
\text { no baço }\end{array}$ & $\begin{array}{l}\text { ICC } \\
\text { LES } \\
\text { IRA }\end{array}$ & Esplenectomia & $\begin{array}{l}\text { Ceftriaxone } \\
\text { Metronidazol } \\
\text { por } 2 \text { dias }\end{array}$ & $\begin{array}{l}\text { Óbito } \\
\text { no 20 DPO }\end{array}$ & $\begin{array}{l}\text { Esplenomegalia } \\
\text { esclerocongestiva com } \\
\text { infartos abscedados }\end{array}$ & $\begin{array}{l}\text { Ponta de catéter: } \\
\text { Staphylococcus } \\
\text { aureus }\end{array}$ \\
\hline $\begin{array}{l}4 \\
F\end{array}$ & 42 & $\begin{array}{l}\text { Dor abdominal } \\
\text { Febre diária }\end{array}$ & $\begin{array}{l}\text { USG/TAC:múltiplos } \\
\text { abscessos esplênicos }\end{array}$ & $\begin{array}{l}\text { Tx Renal } \\
\text { há } 4 \text { anos }\end{array}$ & Esplenectomia & $\begin{array}{l}\text { Ceftriaxone } \\
\text { Metronidazol } \\
\text { por } 3 \text { dias }\end{array}$ & $\begin{array}{l}\text { Obito } \\
\text { no 3o DPO }\end{array}$ & Tuberculose esplênica & Negativas \\
\hline $\begin{array}{l}5 \\
M\end{array}$ & 77 & $\begin{array}{l}\text { Dor abdominal } \\
\text { Febre diária } \\
\text { Diarréia crônica }\end{array}$ & $\begin{array}{l}\text { USG/TAC:abscesso } \\
\text { esplênico único de } \\
10 \times 7,5 \mathrm{~cm}\end{array}$ & $\begin{array}{l}\text { ICC } \\
\text { Endocardite } \\
\text { Cirurgia cardiaca }\end{array}$ & $\begin{array}{l}\text { Drenagem } \\
\text { percutânea }\end{array}$ & $\begin{array}{l}\text { Imipenen } \\
\text { Linezolida } \\
\text { por } 21 \text { dias }\end{array}$ & $\begin{array}{l}\text { Alta } \\
\text { no } 250 \text { DPO }\end{array}$ & - & $\begin{array}{l}\text { Hemocultura: } \\
\text { Staphylococcus } \\
\text { aureus }\end{array}$ \\
\hline $\begin{array}{l}6 \\
F\end{array}$ & 72 & $\begin{array}{l}\text { Dor abdominal } \\
\text { Febre diária } \\
\text { Perda de peso }\end{array}$ & $\begin{array}{l}\text { USG/TAC:abscesso } \\
\text { esplênico multiloculado }\end{array}$ & $\begin{array}{l}\text { Hipotireoidismo } \\
\text { HAS }\end{array}$ & Esplenectomia & $\begin{array}{l}\text { Ceftriaxone } \\
\text { Metronidazol } \\
\text { por } 14 \text { dias } \\
\end{array}$ & $\begin{array}{l}\text { Óbito } \\
\text { no 80 DPO }\end{array}$ & $\begin{array}{l}\text { Tuberculose esplênica } \\
\text { com extensas áreas } \\
\text { de necrose }\end{array}$ & Negativas \\
\hline $\begin{array}{l}7 \\
F\end{array}$ & 14 & $\begin{array}{l}\text { Dor torácica } \\
\text { Febre diária } \\
\text { Vômitos } \\
\text { Reaçăo peritoneal }\end{array}$ & $\begin{array}{l}\text { USG/TAC: abscesso } \\
\text { único, grande }(15 \times 13 \mathrm{~cm})\end{array}$ & $\begin{array}{l}\text { Puerpério } \\
\text { Endocardite }\end{array}$ & $\begin{array}{l}\text { Drenagem } \\
\text { percutânea e } \\
\text { Esplenectomia }\end{array}$ & $\begin{array}{l}\text { Ceftriaxone } \\
\text { Tazobactan } \\
\text { Vancomicina }\end{array}$ & $\begin{array}{l}\text { Sepse pós } \\
\text { drenagem } \\
\text { Alta 180 DPO } \\
\text { esplenectomia }\end{array}$ & $\begin{array}{l}\text { trombose artéria } \\
\text { esplênica, necrose } \\
\text { extensa }\end{array}$ & Negativas \\
\hline
\end{tabular}

DPO: Dia do pós-operatório, ICC: Insufiência cardíaca congestiva, HAS: Hipertensão arterial, LES: Lúpus eritematoso sistêmico, IRA: Insuficiência renal aguda, TAC: Tomografia computadorizada, Tx Renal: Transplante renal, USG: Ultra-sonografia, M: masculino, F: feminino. 


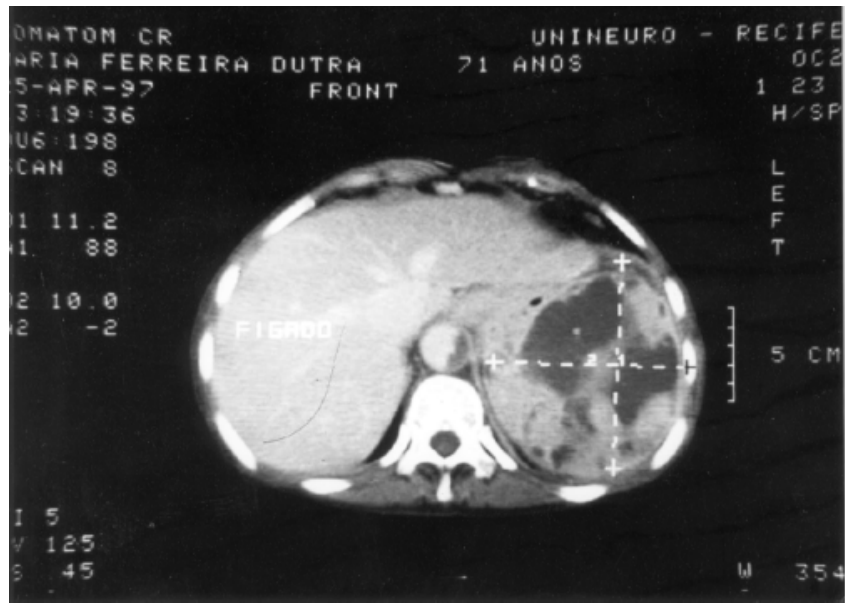

Figura 2 - Caso 5. Tomografia computadorizada do abdome. Abscesso esplênico multiloculado.

gem houve piora do quadro séptico (portadora de endocardite), e optou-se pela realização da esplenectomia.

A média da permanência hospitalar foi de 20,2 dias, variando de 15 a 25 dias. A mortalidade foi de $43 \%$. Dois óbitos ocorreram no período pós-operatório imediato, entre o $2^{\circ} \mathrm{e} 3^{\circ}$ dia pós-operatório (DPO). O óbito mais tardio ocorreu no $8^{\circ} \mathrm{DPO}$.

\section{DISCUSSÃO}

O primeiro relato de tratamento do abscesso esplênico foi em 1733. Em 1874, foi descrito um caso de abscesso de origem traumática curado com aspiração pneumática per-operatória ${ }^{10}$.

Historicamente, o tratamento do abscesso esplênico pode ser divido em duas fases. Ate o final do século XIX, o tratamento mais comum era a drenagem de abscessos avançados, usualmente decorrentes de malária e febre tifóide, que afloravam na parede tóraco-abdominal. Apenas sete esplenectomias haviam sido descritas até 1891. A partir do séc $\mathrm{XX}$, com o advento da anestesia, a esplenectomia para tratamento dessas lesões passou ser a principal forma de tratamento e já em 1907, Kuttner descrevia 116 casos tratados dessa forma ${ }^{10}$.

$\mathrm{O}$ advento dos antibióticos proporcionou a introdução do conceito de tratamento clínico dessa doença, o que provocou grande discussão ${ }^{5}$.

Embora esses marcos históricos tivessem determinado uma mudança nas formas de tratamento da doença, seu diagnóstico continuava a ser feito tardiamente. Foi a partir da década de 70, com a ampliação do arsenal de métodos de imagem e o surgimento da ultra-sonografia, tomografia e ressonância magnética no cenário clinico, que ocorreu uma revolução no diagnóstico do abscesso esplênico ${ }^{10}$

Recentemente, as estatísticas demonstraram um aumento na incidência dessa afecção proveniente das novas condições predisponentes (transplante, AIDS) e do advento de métodos de imagem específicos ${ }^{7}$.

Na literatura, a causa de coleção supurativa esplênica mais prevalente é a infecção metastática. A endocardite e a infecção em sítios distantes representam mais de dois terços de todos os casos ${ }^{11,12}$. Do ponto de vista etiológico, os abscessos estão geralmente associados a outras doenças e classificadas de acordo com a sua patogênese em cinco categorias ${ }^{5}$ :

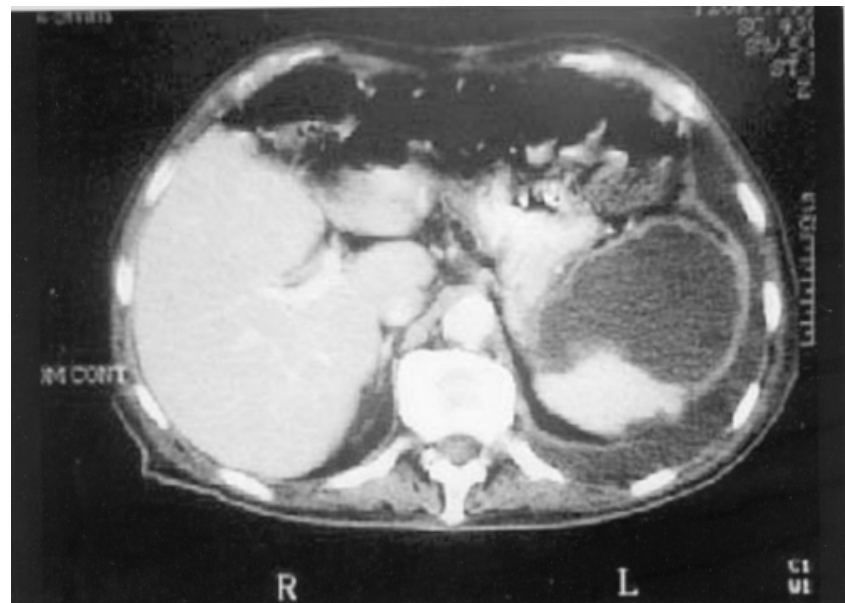

Figura 3 - Caso 6. Tomografia computadorizada do abdome com contraste. Observe o realce do abscesso esplênico extenso.

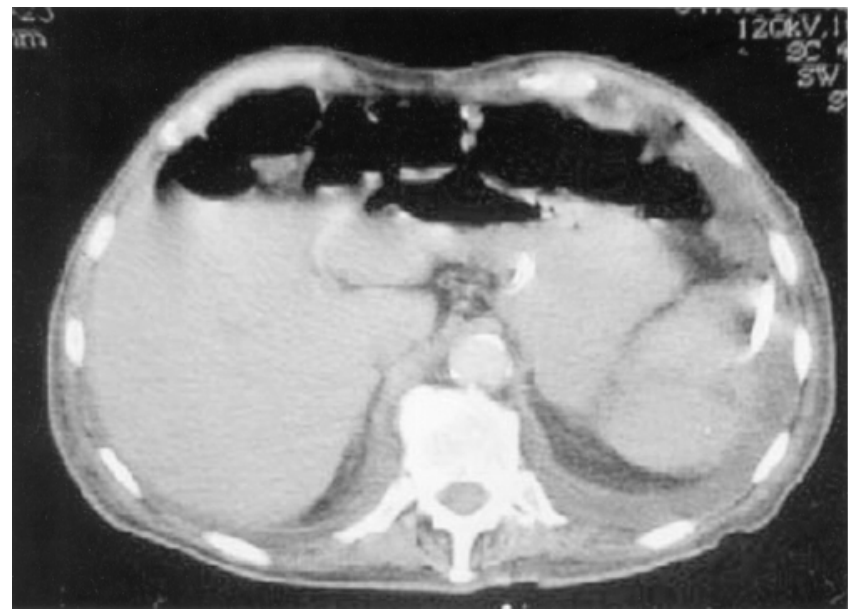

Figura 4 - Caso 6. Tomografia computadorizada do abdome no $9^{\circ}$ dia pós-drenagem. O cateter de drenagem percutânea esta na loja esplênica e houve desaparecimento do abscesso.

- Hematogênico: 75\% do total, sendo a principal causa embolia séptica secundária à endocardite bacteriana;

- Contiguidade: processos infecciosos instalados em órgãos adjacentes, como úlceras pépticas perfuradas, pancreatite e empiema pleural, com 3,5\% de incidência;

- Hemoglobinopatias: como em pacientes com anemia falciforme ou hemolítica, que apresentam três vezes mais chances de ter um abscesso esplênico do que a população geral (12\%);

- Trauma: correspondendo a aproximadamente $17 \%$ dos casos;

- Imunossupressão: uso de drogas imunossupressoras, diabetes, tuberculose, amiloidose e doenças mieloproliferativas.

Relatos recentes apontam para uma mudança nos pacientes acometidos. Atualmente há um aumento no número de pacientes imunossuprimidos, com HIV, doenças malignas e em uso de quimioterápicos imunossupressores, como em pósoperatório de transplantes. Uso de drogas ilícitas injetáveis configura-se numa nova etiologia ${ }^{13,15}$, mesmo que freqüentemente associada à endocardite. Assim como na literatura, encontramos o abscesso esplênico associado a pacientes críticos, população esta típica de um serviço terciário e quaternário dentro de uma estrutura de saúde pública, como o 
Hospital das Clínicas da Universidade Federal de Pernambuco ${ }^{14}$.

Apenas um paciente da nossa casuística era do sexo masculino. Na verdade, as casuísticas normalmente revelam uma predominância desse sexo. Descreve-se ainda uma distribuição bimodal em relação à idade, com picos na $3^{\circ}$ e $6^{\circ}$ décadas de vida. Nos mais jovens observam-se condições como SIDA, endocardite, hemoglobinopatias e uso de drogas. Já o segundo pico é composto de idosos, diabéticos, portadores de câncer e infecções hematogênicas por endocardite ${ }^{10}$.

Sinais e sintomas típicos (febre, dor e esplenomegalia) estão presentes em $50 \%$ ou menos dos pacientes. Por isso, sugere-se que o diagnóstico deve ser suspeitado em qualquer paciente com dor em abdome superior esquerdo e sinais de sepse. Quatro dos nossos pacientes apresentaram essa tríade (57\%) (Tabela 1).

Os sintomas mais frequentes são a dor abdominal e a febre. A dor se expressa no quadrante superior esquerdo do abdome e hemitórax esquerdo, podendo haver irradiação para o ombro esquerdo, sintoma este predominante entre as queixas apresentadas por seis casos levantados (85\%). Calafrios, náusea, vômitos e a sensação de massa abdominal também podem estar presentes. Febre e leucocitose são comuns ${ }^{16}$.

Vários achados radiográficos são descritos, como a presença de gás fora do trato digestivo no quadrante superior esquerdo do abdome; deslocamento da flexura esplênica do cólon, rim esquerdo e sombra gástrica; elevação da hemi cúpula diafragmática esquerda, com ou sem derrame pleural ${ }^{16,17}$ (Figura 1). Radiografias de tórax mostram anormalidades em $82 \%$ dos casos e do abdome em $69 \%$, porém sem especificidade ${ }^{18}$.

O diagnóstico, que era basicamente feito em autópsias, tem melhorado bastante. A expansão da utilização da tomografia computadorizada permitiu o estabelecimento do diagnóstico e do planejamento da abordagem ao demonstrar o número, localização dos abscessos e a presença de doenças abdominais associadas. A tomografia computadorizada é o principal exame complementar na definição diagnóstica desses pacientes ${ }^{19}$.

O abscesso esplênico é considerado uma condição de risco de vida. Se não tratado, evolui com mortalidade de aproximadamente $100 \%$. Tradicionalmente, o tratamento de escolha tem sido a esplenectomia, procedimento que nesta situação está relacionado com uma morbidade e mortalidade elevadas (50\% e $14 \%$ respectivamente) ${ }^{10}$.
Desde o final da década de 80, a drenagem percutânea tem sido realizada como método alternativo para o tratamento das coleções esplênicas, evitando a disfunção imunológica pós esplenectomia ${ }^{8}$. Trata-se de um método cada vez mais pertinente em casos de abscessos únicos, sem septações e com conteúdo fluido, nos quais há um elevado risco na realização da esplenectomia devido à co-morbidades e instabilidade do quadro clínico, podendo servir como medida temporária para a estabilização do paciente e condução do mesmo para a esplenectomia. No início, a difícil aceitação deste método ocorreu devido ao risco potencial de sangramento e pelo perigo de lesão dos órgãos circunvizinhos (principalmente estômago e ângulo esplênico do cólon) $)^{12}$.

Na verdade, uma análise da literatura de 1986 a 1992 revelou que tanto a esplenectomia (87 casos) quanto à drenagem percutânea (47 casos) tem suas indicações próprias. A partir de 1986, vários relatos têm demonstrado a segurança e a efetividade da drenagem percutânea levando a uma taxa de cura de $70 \%{ }^{12}$. Também devemos levar em conta a redução dos custos e dos riscos em longo prazo da esplenectomia, principalmente em jovens ${ }^{10,20}$.

Para alguns, a drenagem percutânea pode ser uma técnica superior à esplenectomia ${ }^{12,21,22}$. Neste trabalho, ${ }^{21}$ a mortalidade da esplenectomia foi alta (14\%) comparada com a mortalidade da drenagem percutânea (2\%, sendo um em 47 casos). A drenagem percutânea não foi bem sucedida em cinco pacientes (11\%) que foram tratados com sucesso através de esplenectomia. É possível que em certos pacientes de alto risco a drenagem percutânea de abscessos esplênicos diminua a mortalidade quando comparada à esplenectomia, devido à sua menor invasividade ${ }^{12,21,22}$, fato este observado na nossa casuística, em que um paciente (número 6), devido às graves co-morbidades associadas, como insuficiência cardíaca congestiva grave e passado recente de revascularização miocárdica, foram decisivas na escolha pelo tratamento percutâneo, que neste caso, foi curativo.

Classicamente, a drenagem percutânea é indicada quando o abscesso é único, sem septações e de material pouco espesso. A formação de um abscesso a partir de um hematoma é um mau prognóstico para a resolução percutânea ${ }^{21,22}$. São contra-indicações para o método: condição abdominal que necessita de reparo cirúrgico associado, ruptura de abscesso com sangramento, coagulopatia, abscessos múltiplos e/ou septados, ascite difusa e ausência de janela radiológica segura para tal procedimento ${ }^{21,22}$.

\begin{abstract}
Background: Splenic abscess remains a diagnostic challenge with a high mortality rate. Its origin is related to episodes of bacteremia after a splenic infarct. Last decade, the demographics of the population with this disease changed towards patients with immunosuppressive conditions (tuberculosis, cancer, transplant, etc). Traditionally, splenectomy has been the treatment of choice, with a high morbidity and mortality. Percutaneous drainage can be an alternative to avoid splenectomy. Methods: A direct search of Hospital das Clínicas/UFPE records between November/1993 and February/2004 resulting in a total number of 73094 patients has been perfomed. Results: Seven cases of splenic abscess are presented: five patients were treated with splenectomy and two with percutaneous drainage. Four patients (57\%) had splenic abscess related to immunosuppressive conditions (steroids, cancer, tuberculosis and transplant). Conclusions: A change in clinical presentation towards imunosupression was observed. The diagnosis should be considered in a patient with fever, abdominal pain and immunosuppressive condition. The percutaneous drainage alone or preceding splenectomy can be efficient to solve splenic abscess in selected cases.
\end{abstract}

Key words: Abscess; Spleen; Splenectomy; Drainage; Infection; Imunosupression; Risk factors; Therapy. 


\section{REFERÊNCIAS}

1. Chulay JD, Lankerani MR. Splenic abscess. Report of 10 cases and review of the literature. Am J Med. 1976;61(4):513-22.

2. Reid SE, Land SJ. Abscess of the spleen. Am J Surg 1954; 88:9127.

3. Hippocrates. Oeuvres Completes D‘Hippocrate. Émile Littre (ed). Libraire de l`Acadamia Nationale de Medicine.1849;6:155230.

4. Chun SH, Raff MJ, Contreras L, et al. Splenic abscess. Medicine.1980; 59(1):50-65.

5. Gadacz TR. Splenic abscess. World J Surg. 1985;9(3):410-5.

6. Caldarera E. Acute abscess of the spleen. Surg Gynecol Obstet.1938; 67:265-7.

7. Nelken N, Ignatius J, Skinner M, et al. Changing clinical spectrum of splenic abscess. A multicenter study and review of literature. Am J Surg.1987; 154(1):27-34.

8. Gleich S, Wolin DA, Herbsman H. A review of percutaneous drainage in splenic abscess. Surg Gynecol Obstet.1988; 167(3):211-6.

9. Moosa MR, Pillans PI. Solitary abscess of the spleen. A report of 2 cases. S Afr Med J.1985;68(1):46-8.

10. Petroianu A. O Baço. São Paulo: CLR Balieiro; 2003.

11. Teich S,Oliver GC, Canter JW. The early diagnosis of splenic abscess. Am Surg.1986;52(6):303-7.

12. Robinson SL, Saxe JM, Lucas CE, Arbulu A, et al. Splenic abscess associated with endocarditis. Surgery.1992;112(4):781-6; discussion 786-7.

13. Avisse C, Delattre JF, Ouedraogo T, et al. Les abces de la rate. Interet du drainage percutane echoguide a propos de quatre nouveaux cas. J Chir.1994;131(10):423-9.
14. Gadacz T, Way LW, Dunphy JE. Changing clinical spectrum of splenic abscess. Am J Surg. 1974;128(2):182-7.

15. Fry DE, Richardson JD, Flint LM. Occult splenic abscess: an unrecognized complication of heroin abuse. Surgery. 1978;84(5):650-4.

16. Ho HS, Wisner DH. Splenic abscess in the intensive care unit. Arch Surg. 1993;128(8):842-6; discussion 846-8.

17. Tikkakoski T, Siniluoto T, Paivansalo M, et al. Splenic abscess Imaging and intervention. Acta Radiol. 1992;33(6):561-5.

18. Kolawole TM, Bohrer SP. Splenic abscess and the gene for hemoglobin S. Am J Roentgenol Radium Ther Nucl Med. 1973;119(1):175-89.

19. Phillips GS, Radosevich MD, Lipsett PA. Splenic abscess: another look to an old disease. Arch Surg. 1997;132(12):1331-5; discussion 1335-6.

20. Sarr MG, Zuidema GD. Splenic abscess-presentation, diagnosis and treatment. Surgery.1982;92(3):480-5.

21. Ben Miled-M`Rad K, Hendaoui L, Ben Thabet I, et al. Drainage percutane des collections spleniques. A propos de quatre observations. Ann Radiol.1993;36(4):281-5.

22. Thanos L, Dailiane T, Papaioannou G et al. Percutaneous CTguided drainage of splenic abscess. AJR 2002;179:629-632.

Endereço para correspondência:

Antonio Cavalcanti de Albuquerque

Rua Deputado Pedro Pires Ferreira, 325/ 1601

Graças

52050-480 Recife - PE

(81)99738223, (81)32672670

acam@elogica.com.br 